\title{
O GÓTICO DE MME CHRYSANTHÈME: CRIMES E MENTES PERTURBADAS EM A MULHER DOS OLHOS DE GELO (1935) ${ }^{1}$
}

Ana Paula Araujo dos Santos Lais Alves de Souza da Silva

Resumo: Este artigo pretende contribuir para os estudos voltados à escritora carioca Cecília Bandeira de Melo Rebelo de Vasconcelos (18701948), que escrevia sob o pseudônimo Mme Chrysanthème ou apenas Chrysanthème. Propomos uma leitura de sua novela $A$ mulher dos olhos de gelo (1935) sob a perspectiva do Gótico literário. Nosso objetivo é analisar como Chrysanthème utiliza o Gótico para 1) narrar uma trama centrada em um crime; e 2) criar perfis de personagens mentalmente perturbados, afetados pela religião e por transgressões cometidas no passado. Ao adotarmos essa perspectiva, buscamos, também, ressaltar a importância da obra dessa escritora para a literatura feminina brasileira novecentista.

Palavras-chave: Narrativa. Século XX. Literatura Brasileira. Gótico. Chrysanthème. Cecília Bandeira de Melo Rebelo de Vasconcelos.

Abstract: This paper aims to contribute to the studies on Brazilian writer Cecília Bandeira de Melo Rebelo de Vasconcelos (18701948), who wrote under the pseudonym Mme Chrysanthème or just Chrysanthème. We propose a reading of her novella $A$ mulher dos olhos de gelo [The icy gaze woman] (1935) from the perspective of Gothic literature. Our purpose is to analyze the ways Chrysanthème uses Gothic to 1) narrate a crime-centered plot, and 2) create profiles of mentally disturbed characters affected by religious beliefs and by transgressions committed in the past. By adopting this perspective, we also seek to highlight the importance of her work for the Brazilian Twentieth-Century Female literature.

Keywords: Narrative. Twentieth Century. Brazilian literature. Gothic. Chrysanthème. Cecília Bandeira de Melo Rebelo de Vasconcelos.

1 O presente trabalho foi realizado com o apoio da Coordenação de Aperfeiçoamento de Pessoal de Nível Superior - Brasil (CAPES) - Código de Financiamento 001. 


\section{INTRODUÇÃO}

A julgar pelo nosso cânone ficcional e por grande parte dos manuais de literatura, parece que poucas mulheres foram escritoras bem-sucedidas no Brasil. Se fôssemos enumerá-las, a lista começaria em meados do século XX, com Rachel de Queiroz, Clarice Lispector, Lygia Fagundes Telles, e contaria com outros poucos nomes femininos dignos de destaque entre uma infinidade de nomes masculinos que aparentemente foram os principais responsáveis por conferir à literatura brasileira a feição que ela possui. Essa suposição não poderia estar mais errada. Em 1950, a historiógrafa Lúcia Miguel Pereira - ela própria autora de romances apontou, em Prosa de ficção, como a falta de escritoras em nossa literatura se deve, na verdade, a uma falha de nossos estudos literários: o silêncio tácito de nossos críticos e historiógrafos, que deram pouca atenção à escrita feminina e não registraram a contribuição das mulheres à literatura brasileira (PEREIRA, 1988, p. 259).

A crítica feita por Pereira se confirmaria nas décadas seguintes à medida que estudos de cunho feminista começaram a ganhar força no Brasil. Se, por um lado, eles ajudaram a reavaliar questões e personagens femininas em obras de escritores canônicos - como D. Casmurro (1899), de 
Machado de Assis, por exemplo -, por outro, se dispuseram a resgatar o nome e as obras de muitas escritoras que não apenas ficaram de fora de nosso cânone literário, como também foram apagadas de nossos registros históricos. Esse trabalho de resgate revelou um sem-número de mulheres que publicaram obras de gêneros variados sobre os mais diferentes temas. Romancistas como Ana Luísa de Azevedo Castro, Maria Firmina dos Reis, Francisca Diniz, Júlia Lopes de Almeida, Emília de Freitas; poetisas como Narcisa Amália e Auta de Souza; e jornalistas e cronistas como Carmem Dolores e Josefina Álvares de Azevedo comprovam que a escrita feminina no Brasil foi bastante profícua antes mesmo da publicação de O Quinze (1930) ou Perto do Coração Selvagem (1943). A despeito do que a nossa historiografia nos fez acreditar, escritoras como Queiroz e Lispector são, em verdade, parte de uma tradição literária feminina que existe desde o Brasil do século XIX.

Mais recentemente, algumas de nossas primeiras romancistas têm ganhado a atenção que lhes fora negada pelos estudos literários à época de suas publicações. A recuperação de suas obras funcionou como um estopim para que elas ganhassem novas edições e se transformassem em objetos de pesquisas acadêmicas interessadas em analisá- 
las sob as mais diferentes perspectivas, valendo-se, por exemplo, das teorias dos estudos culturais, dos estudos feministas, dos estudos do gótico e do fantástico, entre outras. Prova disso é Úrsula (1859), de Maria Firmina dos Reis. Relançado por diferentes editoras, o romance contará com uma tradução para o inglês, que, prometida para o ano de 2020, ainda se encontra em desenvolvimento, e ganhou destaque não apenas por ser um dos primeiros de autoria feminina publicados no Brasil, mas, principalmente, pelo seu discurso abertamente abolicionista que, defendido por uma escritora negra, seria anterior ao de obras canônicas como os poemas de Castro Alves (LOBO, 2006, p. 193). Outra escritora oitocentista que adquiriu recente notoriedade foi Emília Freitas, cuja obra $A$ Rainha do Ignoto (1899), taxada anteriormente como um "dramalhão inverossímil" (MONTENEGRO, 1953, p. 76), também tem sido frequentemente reeditada e estudada como uma das narrativas precursoras da literatura fantástica no Brasil.

Esse importante momento de recuperação e reavaliação de nossa literatura feminina tem ajudado a reconstituir a difícil trajetória das mulheres nas Letras. No entanto, muitas outras escritoras são, ainda, praticamente desconhecidas e carecem de uma fortuna crítica que contemple suas 
obras. É o caso da carioca Cecília Bandeira de Melo Rebelo de Vasconcelos (1870-1948), que escrevia sob o pseudônimo Mme Chrysanthème ou apenas Chrysanthème. Recentemente, a pesquisadora Rosa Gens (2016) chamou atenção para o fato de que Cecília Vasconcelos permanece incógnita: há poucos trabalhos acadêmicos dedicados à sua obra², e, apesar de possuir uma produção literária que conta com mais de quinze romances, livros de contos, peças teatrais e uma vasta quantidade de crônicas publicadas em importantes jornais da época, apenas o romance Enervadas (1922) possui uma edição atual, publicada em 2019 pela Editora Carambaia ${ }^{3}$.

Diante disso, este trabalho pretende contribuir para os estudos voltados a essa escritora carioca de personalidade e obra ímpares ao propor uma leitura do romance $A$ mulher dos olhos de gelo (1935) sob a perspectiva do Gótico literário. Nosso objetivo é analisar como Chrysanthème utiliza a poética gótica para 1) narrar uma trama centrada

2 Além das pesquisas pioneiras empreendidas por Maria de Lourdes de Melo Pinto (2006) e por Rosa Gens (2016), uma rápida busca revela que a vida e a obra de Chrysanthème foram temas dos trabalhos de outros pesquisadores, como José Pedro Toniosso e Mariângela Alonso (2009), Luciana Maria da Conceição Vieira (2015), Maria de Lourdes da Silva, Helena Maria Alves Moreira e Luciana Maria da Conceição Vieira (2016a; 2016b), Eurídice Figueiredo (2019), Mariana Fortes Maia (2020), Marissa Gorberg (2020) e Ana Paula Araujo dos Santos (2020), que listamos aqui com a intenção de demonstrar o ainda tímido interesse dos nossos estudos literários pela escritora carioca, e, ao mesmo tempo, divulgar a sua nascente fortuna crítica.

3 Algumas das obras de Mme Chrysanthème - incluindo a novela analisada neste artigo encontram-se disponíveis no acervo digital do Laboratório de Estudos de Literatura e Cultura da Belle Époque (LABELLE) do Instituto de Letras da UERJ: http://labelleuerj.com.br/acervo-digital/ 
em um crime; e 2) criar perfis de personagens mentalmente perturbados, afetados pela religião e por transgressões cometidas no passado. Ao adotarmos essa perspectiva, buscamos, também, ressaltar a importância da obra de Chrysanthème para a literatura feminina brasileira. Nesse sentido, nos guiamos pelo comentário de Elaine Showalter sobre a literatura britânica que, mutatis mutandi, é válido também para a literatura brasileira:

Ao mesmo tempo que se concentra em um pequeno e bem-sucedido grupo de escritoras [Austen, Brontë, Elliot e Woolf], a crítica às obras de romancistas femininas ignora aquelas que não foram "grandes", excluindoas de antologias, histórias, livros didáticos e trabalhos teóricos. Tendo perdido de vista as autoras menores, elos da cadeia que liga uma geração à outra, não tivemos uma compreensão clara das continuidades da escrita feminina, nem informações confiáveis sobre as relações entre a vida das escritoras e as mudanças no status legal, econômico e social das mulheres. (SHOWALTER, 1977, p. 7)

Diante da deficiência apontada por Showalter, acreditamos que somente um estudo que contemple

4 Tal como esta, as traduções de excertos em língua estrangeira ao longo deste artigo são de nossa responsabilidade.

No original: "Criticism of women novelists, while focusing on these happy few [Austen, Brontë, Elliot, Woolf], has ignored those who are not "great," and left them out of anthologies, histories, textbooks, and theories. Having lost sight of the minor novelists, who were the links in the chain that bound one generation to the next, we have not had a very clear understanding of the continuities in women's writing, nor any reliable information about the relationships between the writers' lives and the changes in the legal, economic, and social status of women." 
escritoras "menores", isto é, que foram deixadas à margem do cânone, pode contribuir para que tenhamos uma ideia mais complexa da tradição literária feminina no Brasil.

\section{CHRYSANTHÈME E A CRÍTICA}

Existem algumas informações que ajudam a entender os motivos pelos quais Mme Chrysanthème teria permanecido por tanto tempo no ostracismo. Em primeiro lugar, Cecília Vasconcelos foi uma figura controversa no meio literário do final do século XIX e meados do XX: se, por um lado, sua biografia revela que se envolvera em escândalos amorosos, responsáveis por influenciar negativamente a recepção crítica de suas obras (PINTO, 2006, p. 133-334), por outro, a leitura de suas crônicas demonstra que ela discursava de forma ousada sobre temas considerados polêmicos, em especial sobre aqueles relacionados à condição feminina. Chrysanthème criou fama em periódicos importantes, como o Correio Paulistano, O Paiz e a Gazeta de Notícias por se mostrar uma defensora incansável dos direitos da mulher na sociedade e uma crítica ferina das instituições que a oprimiam, como o casamento e as leis patriarcais ainda dominantes no Brasil do século XX.

Essa persona não se restringiu às crônicas, pois grande parte de sua ficção apresenta temas e personagens que 
podem ser considerados igualmente polêmicos. Uma análise mais meticulosa de suas obras revela uma arquitetura narrativa que busca, sobretudo, entreter o público leitor por meio de tramas repletas de tabus, transgressões, violências e erotismo. Nas palavras de Rosa Gens:

Pela leitura dos títulos dos seus volumes e dos anúncios que os veicularam nos jornais, fica patente o objetivo da autora de atingir um grande número de leitores, através de uma estratégia de sedução pelo apelo ao erótico, ao moderno, ao violento. Muitas vezes, até ao escabroso. As capas de suas edições também cativam o leitor, através da presença de mulheres nuas, cadáveres, expressões faciais enigmáticas. (GENS, 2016, p. 1114-1115)

Os elementos mencionados por Gens contribuíram para a recepção positiva do público e mesmo alguns críticos toleraram o aspecto chocante de $A$ mulher dos olhos de gelo, enxergando méritos em sua narrativa. À época de sua publicação, os periódicos e as revistas cariocas anunciavam com entusiasmo a nova obra, reportando-se à Chrysanthème como um dos grandes nomes da literatura nacional e mencionando o interesse provocado por seus livros anteriores tanto por seu "tom polêmico" quanto pela "dissecação de pormenores realistas" (CHRYSANTHÈME, 1936, p. 54). Nesse sentido, as narrativas da escritora recorriam a construções 
de personagens baseados em criminosos da vida real ou em indivíduos considerados transgressores pela sociedade de então e a análises de seus processos comportamentais. Publicadas no Diário de Notícias, jornal carioca de grande circulação, as palavras de Evaristo de Moraes atestam a boa impressão causada pelas técnicas literárias da autora:

[...] posso dizer que ainda nesta última produção, demonstra Chrysanthème sua capacidade de sagacíssima observadora da vida real. O que, em regra, ela põe nas suas obras de ficção é aquilo que lhe fornece a visão direta dos fatos e fenômenos, mal percebidos pelo maior número. Aí reside sua qualidade mestra. Nos romances de Chrysanthème não se agitam simples bonifrates, dirigidos por sua fantasia. São os protagonistas, bem como as figuras secundárias, produtos de observação demorada, reproduções de criaturas que a autora submeteu ao exame e à análise, acompanhando-as em determinadas fases das suas existências. (MORAES, 1936, p. 14)

É curioso notar que Evaristo de Moraes era um importante nome da advocacia e da imprensa brasileiras e aparece como personagem em $A$ mulher dos olhos de gelo. O recurso de trazer personagens reais para a ficção, utilizado largamente por escritores realistas, reforça o efeito de verossimilhança na obra. Além disso, por atuar na área criminal, a inclusão de Evaristo parece conferir mais vigor ao estudo psicológico que se faz das personagens. 
Direcionada ao público feminino, a Revista Walkyrias apresentava Cecília como consagrada escritora das letras femininas do país (CHRYSANTHÈME, 1935, p. 8). Exibindo a melodramática capa de $A$ mulher dos olhos de gelo - com o protagonista Maurício em trajes de presidiário, a escrever a sua atormentada história atrás das grades -, a revista registrava que, poucos meses após a publicação pela editora Livraria H. Antunes, o livro encontrava-se praticamente esgotado no Rio de Janeiro. Em abril do ano seguinte, o Jornal Beira-Mar anunciava uma segunda edição aumentada pela escritora, resultado do "sucesso sem precedentes [da] interessantíssima novela" (TORPEZAS..., 1936, p. 5).

O êxito do romance também pode ser observado a partir de uma resposta direta do público. Em matéria intitulada "Três opiniões sobre o último livro de Chrysanthème", o Diário de Notícias (1935, p. 10) publica as impressões de seus leitores, que elogiam o estilo da escritora e o magnetismo da temática: "É o seu romance o verdadeiro modernismo; explorar as paixões humanas, arrancando-as do seu recôndito, e não como se fazia, descrevendo apenas suas explosões".

Embora tenha de fato conquistado o público pelo caráter chocante de sua ficção, de modo geral, esses mesmos 
aspectos de sua obra foram duramente repreendidos pela maior parte da crítica literária da época. Seus principais detratores tinham na moral um argumento infalível para atacar não apenas a vida particular da escritora, mas, principalmente, as suas narrativas. O comentário a seguir, de Agripino Grieco, ilustra tal ponto:

Depois de escrever lindas histórias para crianças [...], Mad. Chrysanthème entrou a escrever livros meio escandalizantes. Passou a por venenos borgianos nas compotas de manga de caju. Seus heróis dantes faziam apenas orgias domésticas com chá, à tisana elegante dos ricos; hoje, atiram-se à morfina e à cocaína. Mad. Chrysanthème descreve, agora de preferência o mostruário de homens da Avenida e suas heroínas praticam uma espécie de donjuanismo feminino. (GRIECO, 1933, p. 183)

Esse tipo de ataque aos "livros meio escandalizantes" é bastante comum à literatura do mal e do medo, isto é, às narrativas que tematizam um lado mais sombrio do ser humano, e se utilizam, para isso, de poéticas negativas, como o horror, o gótico e o sublime. Elas foram julgadas moralmente ofensivas, além de serem consideradas "alienadas", por não trazerem as marcas de nacionalidade valorizadas à época (FRANÇA, 2017, p. 26-8). Essa atitude da crítica condenou ao ostracismo escritores como Franklin 
Távora, Rodolfo Teófilo, Coelho Neto, Gastão Cruls e Cornélio Penna, e, por conseguinte, condenou também a obra de Crysanthème - e de muitas de suas contemporâneas ao completo esquecimento. A escritora, acusada de usar "venenos borgianos" em suas narrativas, e de estimular um "donjuanismo feminismo" com personagens ousadas, ambiciosas e libertinas, pode ser melhor compreendida se levarmos em conta, na leitura de suas obras, o diálogo estabelecido com a literatura gótica, com a prosa decadente, com o naturalismo e até mesmo com a literatura licenciosa brasileira (BROCA, 1991, p. 369-370; SANTOS, 2019, p. 203204; SILVA, 2019, p. 49).

\section{CHRYSANTHÈME E O GÓTICO}

A reconstituição da história das mulheres nas Letras brasileiras revelou, entre outros aspectos, a frequência com que as nossas escritoras se utilizavam da poética gótica em suas obras, a ponto de ser possível falar em uma vertente feminina do Gótico no Brasil (MUZART, 2008; SANTOS, 2017, p. 64-6). Nossas primeiras romancistas escreveram narrativas bastante semelhantes às de Ann Radcliffe, considerada o expoente da tradição conhecida como Gótico feminino. Nelas, as convenções góticas eram utilizadas para narrar terrores e horrores que ameaçavam donzelas 
frágeis e virtuosas em uma sociedade onde imperavam leis patriarcais (SANTOS, 2018).

A relação entre o Gótico e a nossa escrita feminina não se restringiu às escritoras oitocentistas; pelo contrário, adaptouse, no período posterior, às novas tendências literárias, sendo desenvolvida por escritoras como Maura Lopes Cançado, Carolina Nabuco, Lygia Fagundes Telles e Lya Luft, entre outras que utilizaram as convenções dessa literatura para retratar ansiedades femininas ligadas aos distúrbios mentais, à claustrofobia, à agorafobia, aos problemas domésticos, ao lesbianismo, à liberdade sexual da mulher, e à maternidade. Nessa transição do século XIX para o XX, acreditamos que a obra de Chrysanthème tenha se constituído como um importante marco da literatura feminina. Afinal, ela apresenta diferenças formais e temáticas em relação à grande parte das obras de suas antecessoras. Mais notavelmente, suas narrativas não são protagonizadas por mulheres submissas e virtuosas, vítimas de vilões que ameaçam sua castidade e põem suas vidas em risco; pelo contrário, elas procuram retratar um arquétipo diferente de personagem feminina, a mulher moderna brasileira, e têm como foco de suas tramas a sua vida desregrada, não-convencional, adúltera e sexualmente ativa em uma sociedade ainda permeada por preconceitos em relação ao feminino (SANTOS, 2019, p. 201). 
Tomemos como exemplo Maria José, a protagonista de Flores Modernas (1921):

Gozar, era o seu único objetivo na vida. Era moça, julgava-se bonita e possuía, portanto todos os direitos à lisonja, à admiração, às grandezas... O resto, não lhe diria respeito. Falasse, gritasse, censurasse quem quisesse, que, para ela, seria indiferente. E mesmo debaixo dos lençóis, sacudia os ombros com cinismo, como se alguém a estivesse contemplando e ralhando.

O casamento parecia-lhe, a ela, a única porta de saída para a liberdade, e, às vezes, vinha-lhe uma vontade insistente de desposar o primeiro homem que aparecesse, para depois, sob a guarda desse marido ludibriado, mas que ignoraria tudo, poder lançar-se galhardamente no seio de todas as sensações. (CHRYSANTHÈME, 1921, p. 13-4)

Embora não lhe faltem conselhos sobre bondade e virtude feminina, Maria José julga-os valores do passado, preferindo a vaidade e o amor-próprio a qualidades que considera retrógradas. Ela aspira, sobretudo, a uma liberdade que Ihe permitiria gozar da vida e de todas as sensações. Mais afinada ao comportamento das mulheres de seu tempo, revela pouco respeito em relação ao matrimônio: se, para Maria José, casar-se seria a única forma de livrar-se da vigilância e do julgamento da família, o ato não passaria de uma desculpa para o adultério. Essa atitude parece uma reação radical à hipocrisia dos casamentos por 
contrato que, por tanto tempo impostos às mulheres, não raro significavam para elas um destino infeliz.

A mesma vontade de viver sem restrições e experimentar sensações - especialmente as provenientes de experiências sexuais -, é o que move Lúcia, protagonista de Enervadas, a obra mais conhecida de Chrysanthème. Por conta de sua libido, considerada imoral em uma mulher, a personagem é diagnosticada com uma moléstia feminina:

Eu sou, então, uma "enervada"; e tudo isso que me atormenta de dia e de noite, esse atropelo de pensamentos, essa ânsia de gozar a vida, de não perder um bom pedacinho dela, de amar exaltadamente, de aborrecer depois fastidiosamente o que ontem eu adorava, serão os sintomas dessa moléstia que me atacou sem que eu the soubesse o nome?

Mas, Deus meu! todas as minhas amigas são então como eu umas "enervadas", porque me parecem vítimas dos mesmos acessos que me martirizam ou me elevam ao sétimo céu! (CHRYSANTHÈME, 1922, p. 4)

Será ser "enervada" ter-se vontade de beijar um médico moço e bonito que nos visita na intimidade do nosso quarto, que nos apalpa e nos ausculta com carinho e a quem nós confessamos os nossos gostos, os nossos sonhos, os nossos temperamentos? (CHRYSANTHÈME, 1922, p. 7)

O próprio médico de Lúcia, Dr. Maceu Pedrosa, não explica de modo convincente o seu diagnóstico, parecendo 
demasiadamente atraído pela sedutora doente e mais interessado em elogiar a beleza e a elegância desta última (CHRYSANTHÈME, 1922, p. 7). Ao conferir o protagonismo a personagens como Maria José e Lúcia, e retratar mulheres que buscam independência e liberdade sexual, Mme Chrysanthème abriu um espaço na ficção brasileira para personagens femininas que reproduzem a ascensão da Nova Mulher. Surgido em fins do século XIX, concomitantemente à disseminação de novas ideias científicas e culturais - das quais destacamos a chamada Primeira Onda Feminista -, esse fenômeno histórico está ligado às reformulações do papel da mulher na sociedade, bem como à reavaliação de seus direitos políticos e individuais. Gradativamente, o ideal de mulher casta e virtuosa que, restrita ao lar e à família, possuía no casamento o único destino possível, foi substituído pela concepção de uma figura feminina mais independente, instruída e consciente de sua importância nas esferas doméstica e social. O fenômeno materializouse na literatura da época, em obras de escritoras como Sarah Grand, Mona Caird e Kate Chopin e de escritores e dramaturgos como Henry James, Thomas Hardy e Henrik Ibsen. Ora como protagonistas, ora como personagens secundárias, as Novas Mulheres questionavam abertamente os preconceitos de gênero e os seus papeis sociais: 
A Nova Mulher manifestava-se de forma multifacetada na ficção e na imprensa periódica durante as duas últimas décadas do Oitocentos. A "mulher selvagem", a "exaltada solteirona", a "mulher à frente de seu tempo", a "mulher excêntrica", a "mulher moderna", a "Novíssima", as "irmãs estridentes", as "filhas rebeldes" - todas essas construções discursivas aproximavamse variadamente da Nova Mulher nascente. (LEDGER, 1997, p. 2-3) ${ }^{5}$

Na literatura gótica, o novo perfil feminino concorreu para a construção de figuras transgressoras e potencialmente monstruosas. A liberdade sexual e a crescente autonomia nas questões relacionadas ao matrimônio foram os aspectos da Nova Mulher que, amalgamados a outro arquétipo feminino - o da femme fatale -, resultaram em personagens que ameaçavam as ideias convencionais de feminilidade. É o que se constata em duas obras canônicas do Gótico literário do final do século XIX: Carmilla (1872), de Sheridan Le Fanu, e Drácula (1897), de Bram Stoker. Sem sombra de dúvida uma mulher fatal, a vampira de Le Fanu incorpora também uma postura independente e ativa que a aproxima do novo ideal de mulher vitoriana. Já em Drácula, Stoker, ciente da revolução comportamental iniciada na Inglaterra,

5 No original: "The New Woman had manifested herself in multifarious guises in fiction and in the periodical press throughout the 1880's and 1890's. The 'wild woman', the 'glorified spinster', the 'advanced woman', the 'odd woman', the 'modern woman', 'Novissima', the 'shrieking sisterhood', the 'revolting daughters' - all these discursive constructs variously approximated to the nascent New Woman." 
utiliza-se das falas de Lucy para ironizar a Nova Mulher. Em determinado momento da narrativa, o termo é mencionado pela própria personagem que, ocupando-se de atividades consideradas tradicionais demais - o chá da tarde inglês -, parece posicionar-se contra a conduta mais revolucionária das new women: "Creio que a 'Nova Mulher' teria se escandalizado com o nosso apetite"6 (STOKER, 1994, p. 110). Apesar desse comentário, Lucy demonstra possuir, ela mesma, alguns atributos específicos da Nova Mulher, tais como uma postura mais liberal em relação ao casamento e, por consequência, a parceiros sexuais: "Por que uma moça não pode casar-se com três homens, ou quantos a queiram, e evitar todo esse problema?"7 (STOKER, 1994, p. 76). As características da New Woman e da femme fatale mesclamse com a transformação em vampira, em que Lucy se torna definitivamente uma predadora e, por conseguinte, uma ameaça para os personagens masculinos.

Um olhar mais atento para a obra de Chrysanthème torna possível notar que a escritora parecia interessada não apenas em traçar o perfil ficcional dessa Nova Mulher, mas também em outros perfis, especialmente aqueles cujas perturbadoras psicologias pudessem entreter e chocar 6 No original: "I believe we should have shocked the 'New Woman' with our appetites."

7 No original: "Why can't they let a girl marry three men, or as many as want her, and save all this trouble?" 
os leitores. Como muitos outros escritores e escritoras góticas, ela está interessada em um lado mais decadente do ser humano:

A bondade, seja em termos morais, estéticos ou sociais, não se faz presente nos textos góticos. É o vício que lhe interessa: os protagonistas são egoístas ou maus; as tramas envolvem decadência ou crimes. Seus efeitos, estéticos e sociais, são repletos de características negativas - não há beleza, nem demonstrações de harmonia ou proporção. Deformados, obscuros, feios, lúgubres e completamente avessos aos efeitos do amor, da afeição ou dos prazeres nobres, os textos góticos inscrevem a repulsa, o ódio, o medo, a aversão e o terror. (BOTTING, 2014, p. 2) ${ }^{8}$

Para dar conta de transpor tal conteúdo para a ficção, os escritores góticos valem-se de determinadas características narrativas, a saber: i) um locus horribilis como principal espaço narrativo; ii) uma personagem monstruosa como antagonista; e iii) segredos e crimes do passado que retornam para assombrar, metafórica ou literalmente, o presente diegético, trazendo graves consequências para os personagens. A conjunção desses elementos narrativos é o

8 No original: "Gothic texts are not good in moral. Aesthetic or social terms. Their concern is with vice: protagonists are selfish or evil; adventures involve decadence or crime. Their effects, aesthetically and socially, are also replete with a range of negative features: not beautiful, they display no harmony or proportion. Ill-formed, obscure, gloomy and utterly antipathetic to effects of love, admiration or gentle delight, gothic texts register revulsion, abhorrence, fear, disgust and terror." 
que confere à literatura gótica a sua capacidade de suscitar medo como prazer estético no ato da leitura (FRANÇA, 2017, p. 24-5).

Tais convenções góticas são observáveis na novela $A$ mulher dos olhos de gelo, em que Mme Chrysanthème desenvolve uma trama de suspense que investiga as motivações por trás de um horrível crime: o estrangulamento de Helena pelo seu esposo, Maurício de Alencar. Esse "drama sinistro", ambientado no mais ordinário dos cenários domésticos, "numa casinha de Copacabana" (CHRYSANTHÈME, 1935, p. 19), parece reunir mistérios e crueldades o suficiente para horrorizar os personagens envolvidos, como comprova a reação do Dr. Jorge Cavalcanti, amigo de Maurício, ao saber o que ocorrera com o casal:

O seu egoísmo rebelava-se febrilmente contra aquela sensação de angústia a morder-lhe o peito pelo fato da tragédia sucedida ao camarada, mas, involuntariamente, o pensamento fixo, que ele queria afugentar do cérebro, voltava a este, sem que os seus esforços conseguissem afastá-lo.

$E$ as figuras de Maurício e Helena apareciam e desapareciam no écran da sua mente, como tomando-o por testemunha [...]. E sempre, sempre, Helena a fitá-lo com os seus imensos olhos de gelo, que, 
mau grado seu sangue frio de médico, Ihe causavam funda impressão de mal-estar. (CHRYSANTHÈME, 1935, p. 19, grifo da autora)

Em Jorge, a angústia e o mal-estar causados por tomar conhecimento da tragédia de Helena e Maurício somam-se a uma curiosidade que o impele a analisar os detalhes do crime. Esse misto de horror e atração parece refletir a própria reação do leitor à trama criada por Chrysanthème. Sentimonos, como Jorge, horrorizados pelo ato brutal cometido por Maurício, mas igualmente curiosos para desvendar os fatos que teriam levado ao assassinato de Helena.

Afinal, muito embora a lei tenha condenado Maurício a doze anos e meio de prisão por uxoricídio, meses depois do julgamento, a sentença parece não convencer nem mesmo seu perpetrador, que permanece atormentado na Casa de Correção, na tentativa de recordar o exato momento do crime e as causas que o levaram a cometer tal barbárie.

É nesse sentido que $A$ mulher dos olhos de gelo faz uso de outra característica gótica: o retorno do passado no presente. Ainda que tematize um passado recente em relação ao tempo da diegese, a trama desenvolve-se sob o imperativo do retorno de crimes e transgressões pretéritos que, impossíveis de serem esquecidos, tornam-se fonte de ansiedade e medo. Enclausurado, Maurício se pergunta: 
"Que fazer nessas longas horas, senão refletir num passado doloroso a que se seguiu um presente torturante?" (CHRYSANTHÈME, 1935, p. 89). Como ocorre a muitos outros personagens góticos, a contínua rememoração de eventos pretéritos parece atormentá-lo de tal forma que não permite senão um presente dominado pelo medo e pela angústia. Assim, a temporalidade, na ficção gótica, além de contribuir para os efeitos de terror e horror suscitados pela narrativa, funciona como um importante alerta: o passado não está morto, e é preciso enfrentá-lo como forma de expiação, ou, ao contrário, encarar o seu contínuo retorno e sucumbir ao seu poder de dominar as ações no presente.

O peso do crime torna-se evidente nas mudanças psicológicas e físicas que transformam Maurício - antes um oficial do exército descrito como gentil, nobre e garboso (CHRYSANTHÈME, 1935, p. 20) -, em um homem fleumático, de fisionomia decadente, despido de sua vontade de viver e até mesmo de desejos sexuais (CHRYSANTHÈME, 1935, p. 17). A radical mudança em sua fisionomia e em sua disposição é notada por Jorge em sua visita ao amigo:

Acabara de o encontrar, bem diferente, na Casa de Correção, metido numa libré de detento e com os grandes olhos oblíquos encovados e nevoados de melancolia... [...] enquanto falava, o seu olhar inquieto corria 
do guarda que o vigiava às paredes que o encarceravam... (CHRYSANTHÈME, 1935, p. 18)

A prisão é apontada como sendo a causadora dessa devastadora transformação. O local é o principal espaço narrativo de $A$ mulher dos olhos de gelo, e Chrysanthème utiliza um vocabulário mórbido para torná-lo um locus horribilis capaz de reproduzir nos leitores o estado emocional de tensão e medo experimentados pelos detentos:

A corneta, tocando, marcava as horas lentas e sinistras dessa prisão, encerrando entes humanos. Silêncio, pesado e fúnebre, reinava após esses tons lúgubres, que sinistravam a noite de Deus, que selavam, de horror, a dormida de tantos infelizes, esparsos pelos cubículos de uma casa, criada por uma Justiça, que se diz humana e em defesa de uma sociedade, que se intitula civilizada! (CHRYSANTHÈME, 1935, p. 77)

Ao longo da narrativa, a Casa de Correção é descrita como um "presídio, infecto e infernal" (CHRYSANTHÈME, 1935, p. 80), uma "casa de mortos-vivos" (CHRYSANTHÈME, 1935, p. 111), "nefasta para os homens e maldita por Deus" (CHRYSANTHÈME, 1935, p. 27). À adjetivação lúgubre somase a descrição de uma atmosfera tornada insalubre pela constante exposição à violência e às transgressões:

O ar, que se respira nesta casa, dita de Correção, é mefítico, contendo miasmas 
tremendos e infeccionando mortalmente os que aqui entram mais ou menos sãos, mais ou menos equilibrados. $E$, ontem, deuse, nesta penitenciária, repleta de guardas, de soldados, e de vigilantes, um drama tão repentino, que quase acabou em tragédia sinistra. Dois detentos brigavam por causa ainda ignorada pelo diretor e, aos golpes de facas, aparecidas de repente sangraram-se com a crueldade de feras. O pátio inundou-se do sangue de um deles, vibrou de clamores, de apitos, de tropel de passos e até de tiros, que repercutiam dramaticamente pela casa inteira. Em um segundo, encheu-se o local de pavor, de movimento e de um verdadeiro enxame de guardas, decididos a tudo, porque, afinal, a vida de um preso não conta, nem merece... preocupação. E, se um foi para a enfermaria, o outro foi para a solitária... (CHRYSANTHÈME, 1935, p. 127-128)

Cenas como essa - que banham de sangue os corredores da prisão e enchem os detentos de um misto de pavor e excitação - são narradas de modo a inspirar, no leitor, o horror ao cotidiano carcerário em que a vida diminui de valor por conta da violência onipresente e opressiva. Posteriormente, Maurício descobre que o motivo da briga entre os presos era o relacionamento homoafetivo nascido entre ambos no período do enclausuramento. Essa motivação não parece gratuita, pois também serve como forma de intensificar os efeitos malignos do locus horribilis: 
Das janelas presenciei o incidente e lastimei que essa sociedade, tão defensora dos seus direitos, não tenha visto em que se transformam indivíduos em plena vitalidade, privados das famílias, de praticar os seus atos de homem, exacerbados pela prisão, envenenados por uma atmosfera pestilenta, onde se agitam mentalidades taradas, pela herança, pela sífilis ou pelo álcool. (CHRYSANTHÈME, 1935, p. 128, grifo da autora)

A homossexualidade, considerada, à época, um desvio moral, era encarada como uma doença, e o ato sexual, narrado de modo repulsivo. Ainda assim, após o desenlace de tais acontecimentos, o presídio retorna ao "silêncio, pesado, abafadiço", e se sobressai entre os detentos uma angustiante sensação de impotência (CHRYSANTHÈME, 1935, p. 129). As reflexões de Maurício após o acontecido demonstram que, além do estado de insegurança e de tensão gerado pelo confinamento em um locus horribilis, outro problema afeta os detentos: expostos às transgressões morais e sexuais, a Casa de Correção causa o embotamento das emoções, torna-os gradativamente mais insensíveis aos atos sexuais considerados ilícitos, ao sofrimento, à crueldade, e à morte de seus companheiros: "O presidiário não se espanta de coisa alguma: o seu fundo emotivo está gasto ou suspenso. Ele julga tudo possível e tudo natural. A 
vida, nesta casa, muda de nome e a morte, de expressão..." (CHRYSANTHÈME, 1935, p. 79).

\section{PERFIL DE MAURÍCIO}

Para dar continuidade à análise das convenções góticas em $A$ mulher dos olhos de gelo, resta-nos descrever os monstros humanos, isto é, aquelas personagens cujos atos maus ultrapassam os limites do que consideramos humano. A literatura gótica brasileira está repleta de exemplos de antagonistas que se encaixam nesse arquétipo: senhores de terras e de escravos, patres familias, capatazes, entre outras figuras de autoridade que agiam de forma violenta e tirânica e representavam os medos da aristocracia da terra e de nosso passado colonial. No século $X X$, os representantes desse passado cada vez mais distante foram substituídos por vilões do cotidiano, cujos terror e horror que inspiram não raro estão ligados a distúrbios psicológicos. Chrysanthème procura, em suas narrativas, criar perfis que se destacam por suas mentes perturbadas - loucos, necrosados, doentes, drogados, fanáticos e criminosos - de modo a investigar mais a fundo as suas respectivas transgressões. Em $A$ mulher dos olhos de gelo são as psiquês de Maurício e Helena que se ofertam ao escrutínio dos demais personagens e dos leitores. 
“- Como matei minha mulher?" (CHRYSANTHÈME, 1935, p. 21). Essa questão, levantada por Maurício ao início da novela, é o que serve de motor para o desenvolvimento da história, afinal, ele casara com Helena por acreditarse apaixonado, e seu perfil não parece condizer com o de um assassino. A tensão acerca dessa pergunta aumenta à medida que os fatos vão se desenrolando por meio das confissões de Maurício. Ao rememorar sua relação com Helena e narrar a história de seu casamento, a trama ganha uma conotação de mistério a ser desvendado:

Eles - os juízes, afirmam que assassinei Helena; eles não sabem, porém, como se deu esse estrangulamento e a que força oculta obedeceram as minhas mãos, frias e trêmulas, cerrando-se em torno de seu pescoço, branco e fino, que eu beijara tantas vezes, com paixão e em lágrimas. Eu próprio, na confusão do sumário, durante as interrogações do delegado, escutei-me falar como se escutasse a outrem. E ainda conversando com o meu advogado, o grande Evaristo de Moraes, não consegui dizer, não consegui explicar, como se dera tão horrível sucesso. (CHRYSANTHÈME, 1935, p. 21-2)

Resta-me, agora, relatar o período mais angustioso da minha vida passada, a época mais humilhante da minha existência de homem, aquela, que me conduzia como degraus de uma escada sombria, a este local de trevas, onde agonizo. (CHRYSANTHÈME, 1935, p. 117) 
Tal como em Enervadas, a história desse assassinato é apresentada sob a forma de um diário. O leitor das confissões é Jorge Cavalcanti, cujo interesse no crime mencionamos anteriormente. O médico, versado em psicologia e psicanálise, encara a história do amigo como um estudo de caso, o que faz com que também os leitores assumam essa perspectiva analítica ao longo da obra.

Além disso, os fatos do assassinato são apresentados por um único ponto de vista - o de seu perpetrador - com foco em suas memórias mais íntimas, em suas impressões e reações, garantindo, assim, uma espécie de imersão à mente de um assassino. Essa estratégia narrativa é bastante comum na ficção que busca suscitar efeitos de horror, e, para isso, aposta largamente na narração de atos de violência pelo ponto de vista de criminosos, psicopatas e torturadores como forma de encorajar o leitor a estabelecer vínculos empáticos com o transgressor - e não com a vítima. Embora possa parecer, a princípio, uma atitude moralmente condenável, é possível, por meio da empatia, não apenas se compadecer com o sofrimento da vítima, mas, também, experimentar o prazer do agressor. Essa possibilidade não cria leitores ou espectadores sádicos, mas possibilita - e estimula - fantasias de transgressão na literatura, no cinema ou em outras mídias - sem que se ponha em risco ou que se cause danos às pessoas 
reais (FRANÇA, 2017). Ciente desse artifício narrativo que provoca prazer estético por meio do horror, Chrysanthème procura, ao longo da trama, fazer com que o leitor simpatize com Maurício, permitindo, assim, que se compartilhe da tensão que o levara a cometer um crime e que culmina no horrível êxtase provocado pelo assassinato de Helena.

O drama de Maurício tem início logo após o casamento: a arrebatadora paixão pela bela moça "mignonne e deliciosa" (CHRYSANTHÈME, 1935, p. 18, grifo da autora) leva a um brevíssimo noivado que o previne de saber que Helena e sua família eram católicos fervorosos. O preço desse arrebatamento é pago logo na noite de núpcias, quando Maurício descobre que Helena encara como pecado a perda de sua virgindade:

Ela, como uma cobra desvencilhouse rapidamente dos meus braços e, mergulhando nos meus os seus olhos, semelhantes a lagos sem fundo, exclamou, com azedume e quase violência:

- Vou perder, por tua culpa, a minha virgindade e deixar de ser casta como as esposas de Cristo, declarou-me ela soluçando. (CHRYSANTHÈME, 1935, p. 32-33)

À recusa de Helena, o ato sexual se dá de forma forçada:

E tirando-lhe a imagem [santa] das mãos convulsas, consegui atraí-la para mim! Mas que noite, santo Deus! que noite! Eu tinha a 
impressão de apertar um cadáver junto ao meu coração, cadáver de olhar vidrado e de corpo completamente inerte... Larguei-a, afinal, como se larga um fardo e, em silêncio, num recuo da minhalma e do meu físico, afasteime dela, colocando-me à beira da cama. De súbito, senti que ela se erguia e se ajoelhava no leito, rosnando orações e batendo no peito com os dedos hirtos. Escutei-a também chorar... (CHRYSANTHÈME, 1935, p. 33-34)

Por meio do diário de Maurício temos acesso apenas à sua frustração sexual e à surpresa de se descobrir casado com uma beata para quem a devoção a Cristo era superior aos votos conjugais. Ainda assim, se focarmos nas poucas reações de Helena citadas no excerto, a consumação do matrimônio se dá a partir de um estupro: atraída contra a sua vontade para os braços do marido, ela torna-se um "cadáver de olhar vidrado e de corpo completamente inerte", "um fardo". Depois do ocorrido, Helena sente raiva e chora. Seu comportamento muda drasticamente: "[os] seus largos e gelados olhos tinham adquirido expressão de tal fixidez num qualquer ponto do espaço, que lembrava olhos de sonâmbula ou de magnetizada" (CHRYSANTHÈME, 1935, p. 39). Ela emagrece e se torna quase afônica. A raiva e a repugnância são os únicos sentimentos que nutre pelo marido.

A partir de então, Maurício passa a ser constantemente hostilizado pela esposa e pela família. Para Helena, ele é “o 
monstro que lhe desfolhara a coroa de virgem, o saqueador do tesouro, que ela reservava a Jesus" (CHRYSANTHÈME, 1935, p. 90-91, grifo nosso). A mãe e os irmãos da esposa passam a humilhá-lo e a atormentá-lo, tornando o seu cotidiano na casa de Copacabana um verdadeiro martírio. Em seu diário são descritas inúmeras situações em que ele é oprimido no próprio lar, no qual permanece apenas por amor a sua filha, Guida. Incapaz de se impor e de se defender, é tomado pela angústia de alguém que não enxerga nenhuma saída para uma situação insuportável. De capitão nobre e viril, Maurício torna-se fleumático, nervoso. Ele flerta com o suicídio, e começa a dar indícios de uma iminente degradação mental. A esse respeito, Evaristo de Moraes, ao analisar a obra, chama atenção para o modo como Chrysanthème procura retratar de modo analítico os acontecimentos que levam Maurício à insanidade, e, por conseguinte, ao uxoricídio:
A "angústia mórbida" que atormenta a personagem central, e tanto impressiona os leitores, encontra-se, sem custo, em trabalhos de neurologistas e na intimidade dos manicômios, bem como, sob forma atenuada, no convívio social, dissimulando- se facilmente.
[...]
$O$ que Chrysanthème figurou no seu romance, quanto ao motivo de condenação 
da principal personagem masculina, cabe perfeitamente no quadro das manifestações da neurose. (MORAES, 1936, p. 14)

Se somarmos a narrativa e os comentários do crítico, não restam dúvidas de que Chrysanthème está interessada em investigar como os indivíduos sãos podem, facilmente, tornarem-se vítimas de doenças mentais, e, nas condições adequadas, cometerem horríveis atrocidades. Ao final de seu relato, Maurício parece transformado em um ser mau e monstruoso, pronto para cometer um crime:

Devia estar transfigurado pela cólera e pelo ódio, que me afogavam por dentro, porque observei, na mirada dos seus olhos frios, como uma leve alteração causada pela surpresa da minha nova atitude.

[...]

Ela recuou um pouco e, meus dedos que, das suas espáduas, se dirigiam, automaticamente, a seu rosto, pararam no pescoço, que, como o de uma cobra, se dilatava, cheio de peçonha e de agressão... E, sempre olhos nos olhos, vi-a de repente baquear e estenderse no chão onde continuou a me fitar com aquelas imensas pupilas, em que o gelo se ia vidrando e empanando. Estava morta... (CHRYSANTHÈME, 1935, p. 140-142)

O estrangulamento ocorre num acesso de raiva tão intensa que Maurício pouco se recorda do acontecido. Em suas reflexões, ele admite ser um "delinquente por 
fatalidade" (CHRYSANTHÈME, 1935, p. 124). No entanto, para a família de Helena e para os tribunais que o julgaram, ele é um monstro, um brutal assassino. Mesmo Jorge Cavalcanti, que se comove com o drama do amigo, ao terminar de ler o diário, parece ciente da violência do crime: ele sonha com Helena ostentando o pescoço descoberto, com largas manchas roxas, balançando a cabeça como se, vítima de uma morte atroz, tivesse se transformado em uma horrível fantasmagoria (CHRYSANTHÈME, 1935, p. 146).

A ambiguidade que se constrói na narrativa a respeito do crime se desfaz, no desfecho de $A$ mulher dos olhos de gelo, confirmando a imputabilidade de Maurício após a revisão do caso. A sua libertação da Casa de Correção pode ser melhor entendida se levarmos em conta outro distúrbio mental explorado por Chrysanthème: o fanatismo religioso de Helena.

\section{PERFIL DE HELENA}

Se a ânsia pela liberdade sexual e um intenso desejo carnal eram os traços característicos de suas protagonistas anteriores, Chrysanthème lança mão de uma figura feminina marcadamente destoante em $A$ mulher dos olhos de gelo. Nesta obra, o que choca os leitores não é o comportamento sexual desregrado, mas, pelo contrário, o desmedido 
fanatismo religioso por parte de Helena, que demonstra horror ao sexo ou mesmo a qualquer contato afetuoso de seu marido. Por meio das palavras de Maurício, conhecemos uma mulher excessivamente conservadora, hipócrita e tirânica no relacionamento conjugal.

Desde o início da narrativa, Helena é representada como a figura vilanesca e misteriosa, a cujos pensamentos o leitor tem pouco acesso. O que nela se destaca é o olhar glacial e agressivo, capaz de provocar impressão profunda, tal como revela Jorge, ao se lembrar da esquisita sensação que a mulher do amigo lhe causara quando a conhecera por ocasião do casamento (CHRYSANTHÈME, 1935, p. 9). Os olhos de Helena agem quase como uma força sobrenatural sobre Maurício, consumindo-lhe a força e abatendo-lhe o ânimo. Mesmo na falta de ofensas e humilhações ao marido, ela emana hostilidade. As falas iniciais de Maurício exprimem o mal-estar suscitado apenas pela presença da personagem:

[Ela era] uma inimiga íntima, que [...] vigia sem cessar com um olhar de soslaio, olhar cheio de raiva e de desdém, muda, reservada, na trincheira da sua personalidade, no silêncio da sua boca cerrada. A inquisição não se servia dessa forma de punir, mas, eu te asseguro, que essa forma é tremenda e leva à loucura. Eu a adorava, mas Helena esmagou a minha adoração, lançando, sobre ela, a glacialidade da sua 
indiferença e a pertinácia da sua agressão. (CHRYSANTHÈME, 1935, p. 8-9)

Se a graciosidade da personagem fora responsável por conquistar o amor de Maurício e despertar-lhe adoração no breve período do noivado, os momentos iniciais do matrimônio ditariam a direção que o relacionamento não tardaria a tomar. Do trauma do primeiro contato íntimo com o marido, Helena retém profundo ressentimento, e passa a utilizar-se, em um primeiro momento, da frigidez, e, posteriormente, da abstinência sexual para infligir mais sofrimento a Maurício.

Assim, o fanatismo religioso tem papel fundamental, pois degrada tanto os atributos morais quanto a psique da mulher, tornando-a ainda mais perversa. Os primeiros relatos de Maurício já deixam claro o doentio carolismo de Helena: "Jorge, Jorge, tu não sabes e Deus permita que jamais saibas do que é capaz a mulher que maltrata e fere um homem pelo amor de Deus!" (CHRYSANTHÈME, 1935, p. 11, grifo da autora). À pergunta do amigo sobre uma traição de Helena como razão para o monstruoso crime, o ex-capitão responde negativamente, repelindo suspeitas de um adultério mundano: "Não, Jorge, ela foi ferozmente honesta e, se me enganou, fê-lo, certamente, com Jesus" (CHRYSANTHÈME, 1935, p. 11). Maurício entende a imoderada adoração de 
Helena à figura do Cristo como uma infidelidade ainda mais grave, e amortiza sua fúria e frustração com comentários e sugestões sacrílegas: ao descrever a mulher para Jorge, o personagem assinala de maneira irritada a constante presença de Helena nas igrejas, a comer hóstias, em contraste com sua postura de inclemente algoz na intimidade do lar (CHRYSANTHÈME, 1935, p. 11).

A narrativa que o protagonista registra em seu diário expõe de forma dramática a sua vida com a esposa e o restante da família Araújo - composta por D. Isidora, mãe de Helena, Estella e Júlio, seus irmãos -, todos fervorosamente católicos. De classe média e proprietários da casa de Copacabana na qual o casal passa a viver depois do casamento, os familiares de Helena desdenham da posição de Maurício no exército e acusam-no de arruinar a vida da esposa. Dessa forma, eles corroboram com o comportamento hostil de Helena, contribuindo para o clima progressivamente opressivo sentido pelo personagem:

E esses três personagens, carrascos impunes da minha existência, conjuntamente com os padres e freiras, desnorteadores da fraca mentalidade de minha mulher, são os responsáveis pelo crime de que me acusam e, portanto, pela [...] morte [de Helena]. (CHRYSANTHÈME, 1935, p. 31) 
Helena aparece sempre como uma personalidade de poder, dominando Maurício desde o início do relacionamento, como atestam os seguintes trechos: "a sedução exercida por Helena sobre mim anestesiara um tanto o meu raciocínio" e "[d]irão os que me lerem [...] que eu fora muito fácil de iludir... Esse alguém ignora certamente o poder de artifício que minha casta esposa possuía e dispendeu durante nosso curto noivado" (CHRYSANTHÈME, 1935, p. 34 e 54).

Tamanha seria a crueldade da mulher que, ainda que condenado a mais de uma década na Casa de Correção e destituído de seu posto no exército, o protagonista sentese liberto do que considera o pior dos grilhões - os olhares glaciais daquela cuja vida dera cabo:

A certeza de que jamais encontraria, fixos em mim, os terríveis olhos de gelo de Helena, olhos glaciais de inimiga, olhos envernizados de santa, forrados de demência, inflexível e cruel, causava-me certa expressão de alívio. (CHRYSANTHÈME, 1935, p. 22)

Com o nascimento de Guida - por quem o protagonista nutre natural sentimento de proteção paterna -, tem-se o contexto ideal para o prolongamento do drama de Maurício. O militar demonstra diversas vezes medo da influência de Helena e de sua família sobre a mente da menina, e teme que a esposa cumpra os planos de fazer dela uma noviça. 
Além disso, a relação entre mãe e filha parece não possuir laços tão fortes quanto a de Maurício com a criança, uma vez que Helena abdica de seu tempo em casa para dedicarse às missas e aos demais eventos eclesiásticos. A própria Guida parece temer a presença da mãe. Nesse sentido, Helena é descrita como uma figura assustadora, isto é, por conta de seu fanatismo exagerado ela adquire mesmo características monstruosas:

A criança fugiu, debaixo de uma impressão indomável de terror, inspirado pelo rosto fechado de Helena, enquanto eu permaneci no mesmo lugar, analisando a fisionomia agressiva daquela criatura que, segundo a sua crença, acabava de ter contato com um Deus de bondade e de ternura. (CHRYSANTHÈME, 1935, p. 121-122)

Nessa perspectiva, A mulher dos olhos de gelo foi divulgado como um estudo de caso elaborado por Chrysanthème (CARAVALHO, 1934, p. 4; MORAES, 1936, p. 14). É curioso notar que a maioria dos críticos e dos leitores atribuiu tal atividade analítica quase exclusivamente ao caso de Maurício de Alencar. É o que se observa na resenha do advogado Evaristo de Moraes (1936, p. 14), mencionada anteriormente: o criminalista defende que o protagonista de Chrysanthème encaixa-se no quadro neurótico manifestado por indivíduos condenados por diversos crimes, mencionando ter atendido 
a dois clientes que se assemelhavam a Maurício. Porém, não é feita qualquer consideração sobre o perfil de tal "mulher fatal" capaz de levar a tamanho descontrole psíquico. Isso pode explicar-se por ser Moraes um advogado, mais interessado nos aspectos que constituem a defesa de indivíduos indiciados por seus crimes. Contudo, não se encontra outras críticas ou impressões sobre o romance de Chrysanthème que se refiram à questão do perfil de Helena: pouco foi dito ou questionado sobre os processos mentais da mulher que não apenas é aludida no título, como é o agente de todos os conflitos do protagonista. Nos periódicos da época, chega-se a falar de "beatice doentia" (TRÊS OPINIÕES..., 1935, p. 10) e de "uma rapariga de psicologia enigmática" (CHRYSANTHÈME1936, p. 54), mas os comentários não são desenvolvidos. Esse dado permite-nos afirmar que a estratégia narrativa de estimular a simpatia do leitor em relação a Maurício foi lograda, mas acreditamos que Chrysanthème também tencionava explorar a doença de Helena na mesma medida em que se propunha a investigar a decadência moral de Maurício.

Prova disso é a abordagem que a narrativa confere à disfunção psíquica de Helena. Os distúrbios psicológicos parecem fazer parte de sua linhagem familiar: anos atrás, 
uma doença mental fora a responsável por levar seu pai à morte em um hospício: "paranoico varrido, vítima de uma tremenda histeria, de forma também religiosa" (CHRYSANTHÈME, 1935, p. 34). Diante disso, o próprio Maurício passa a considerar a possibilidade de a esposa ser também uma doente: "a minha pobre mulher [...] era a mais fervorosa das fanáticas religiosas, enferma de uma histeria, que só averiguei mais tarde, quando a cura já se tornara de todo impossível" (CHRYSANTHÈME, 1935, p. 31-32, grifo nosso). A confirmação dessa suposta doença se dá a partir de uma conversa entre o protagonista e um médico de seu batalhão acerca do fanatismo religioso:

- Horrível enfermidade e a mais incurável das histerias!...

- Incurável? indaguei, trêmulo e sufocado.

- Sim, tão incurável como a mania de perseguição. De todas as angústias humanas é a mais incurável... Conhece alguém nesse estado?

Hesitei, mas depois respondi:

- Conheço um infeliz, que infelicita os outros. - Compreendo isso, acrescentou, gravemente, o médico. $O$ fanatismo religioso é uma forma de delírio, determinando perigos para os espíritos fracos e ameaças para os que os acotovelam... E as mulheres, sobretudo, facilmente sugestionáveis, são as vítimas escolhidas por tal gênero de moléstia. (CHRYSANTHÈME, 1935, p. 93-94) 
Cabe aqui ressaltar que a histeria está inserida em um grupo de doenças julgadas como particularmente femininas - tal como a origem do termo atesta, hyster, do grego, significa "útero". Por muito tempo, acreditou-se que essa enfermidade fosse causada por um desequilíbrio uterino, mas, a partir do final do século XIX, os estudos acerca da psique humana passaram a considerá-la como um distúrbio mental específico, causado geralmente por coerções, traumas ou desvios relacionados ao comportamento sexual feminino. Nesse sentido, a histeria foi largamente utilizada por autoras do Gótico literário para a construção de narrativas que contemplavam os horrores e terrores da vida das mulheres.

À abordagem da perturbadora psique de Helena, Chrysanthème soma críticas direcionadas à própria igreja católica e aos fiéis. Estes assumem posturas hipócritas no que concerne aos principais preceitos do cristianismo. Além de descrever o fanatismo de Helena, Maurício relata as contradições no comportamento da esposa e de seus familiares, que, embora cercados por imagens religiosas e cumpridores de todas as obrigações ritualísticas da religião, mostravam-se indivíduos mesquinhos, calculistas e cruéis:

Helena, todavia, manifestava na sua psicologia de fanática católica alguns sintomas que me traziam perplexo e desorientado nas minhas observações 
sobre ela. Assim ela adorava o dinheiro, o luxo, as joias, mostrando-se sempre de um orgulho, intransigente e indomável. Em lugar da humildade, apanágio, em geral, dos cristãos, dignos desse nome, ela ostentava sempre intolerância, severidade, falta de doçura e de indulgência para o próximo. E, com o desgraçado que eu já era, nessa época, Helena se apresentou sempre dura, inflexível, exigente de dinheiro, desdenhosa dos carinhos. (CHRYSANTHÈME, 1935, p. 53-54)

[Helena e a sua família] aqueles católicos fanáticos e requintados na crueldade, como todos os beatos que nunca hesitam em maltratar o próximo pelo amor de Deus!

- Minha mulher era uma enferma, vítima da histeria religiosa derivada num fanatismo da pior espécie, dominada por padres e freiras, respirando a atmosfera deprimente dos confessionários e dos cenáculos religiosos, ela tinha perdido a visão e a direção da vida. [...] Em torno dela, a família, intolerante e intransigente, admirava-a e ainda, sob a influência da mesma gente, julgava que maltratar o marido que a perturbara a ponto de levá-la ao casamento era um direito que Ihe vinha do céu. (CHRYSANTHÈME, 1935, p. 135-136)

Aludida no segundo excerto, a questão da influência nociva de uma autoridade religiosa é abordada desde o início da história de Maurício. Um dos exemplos mais contundentes encontra-se na fala de Helena, quando 
se ressente de ter perdido sua virgindade e cita as recomendações do clérigo de sua igreja no que compete à manutenção de sua "pureza espiritual":

Eu era uma prometida de Jesus e, agora, estou enxarcada da lama do pecado contra a castidade. Padre Miguel me aconselha que, quando você quiser usar de mim, eu reze três ave-marias durante $o$ tal ato repugnante e que, dele, não partilhe um só segundo. (CHRYSANTHÈME, 1935, p. 42)

As queixas de D. Malvina, beata amiga da família Araújo, sobre o padre de sua congregação também deixam entrever uma visão mais crítica acerca da interferência religiosa em assuntos íntimos: "[o] fato é que o padre João não andou corretamente com a minha neta, perguntando-Ihe se ela 'praticava ações feias com os irmãos'" (CHRYSANTHÈME, 1935, p. 87, grifo da autora). A senhora surpreende-se quando D. Isidora e Helena não somente aprovam a atitude do clérigo, como opinam que a menina deveria receber um castigo por contar a outrem o conteúdo de sua confissão. É o apoio de Maurício à sua indignação que serve de conforto à Malvina - os dois percebem atitudes impróprias e abusivas por parte dos eclesiásticos, enquanto as duas mulheres permanecem impassíveis a quaisquer reprovação ou julgamentos mais críticos sobre os representantes da igreja. 


\section{CONSIDERAÇÕES FINAIS}

A análise dos perfis de Maurício e de Helena permite-nos concluir que, sob condições e estímulos adequados, qualquer indivíduo pode tornar-se um sujeito monstruoso. Esse é precisamente o mais contundente ensinamento do século XX: mesmo as pessoas aparentemente normais e íntegras estão suscetíveis a sucumbir à pressão psicológica provocada por circunstâncias abusivas e/ou repressoras. Em relação à Helena, a influência perniciosa da família e o excesso de religião transformaram-na em uma mulher hipócrita, tirana e alienada. Como procuramos demonstrar, a personagem, vítima do uxoricídio, está longe de ser apenas uma vítima, pois ela é quem fornece os elementos necessários para a formação e o desenvolvimento da monstruosidade do esposo. Este último, igualmente uma personagem complexa na narrativa de Chrysanthème, pode ser tomado como um homem dominado pela angústia e pelo desespero, acabando por se tonar, ulteriormente, um homicida.

O estudo dos casos psicopatológicos do casal condenado à destruição pode ser sumarizado na fala do personagem de Jorge Cavalcanti, que alerta para os mistérios da mente humana ao dizer que "[o] subconsciente dos indivíduos é um [...] abismo de trevas e de recantos" (CHRYSANTHÈME, 1935, 
p. 153). Interessada em explorar tais mistérios, Chrysanthème demonstra, em $A$ mulher dos olhos de gelo, como o Gótico oferece os recursos adequados para retratar não apenas os horrores visíveis - as violências e os crimes da vida cotidiana -, mas, também, aqueles conflitos mais obscuros e íntimos do ser humano.

\section{REFERÊNCIAS}

BOTTING, Fred. Gothic. 2. ed. London: Routledge, 2014.

BROCA, Brito. Naturalistas, parnasianos e decadistas: vida literária do Realismo ao Pré-Modernismo. Campinas: Editora da UNICAMP, 1991. CARVALHO, Albertus. Livros. Jornal Beira-Mar. Rio de Janeiro, p. 4, 28 setembro de 1935.

CHRYSANTHÈME [Cecília Bandeira de Melo Rebelo de Vasconcelos]. A mulher dos olhos de gelo. Rio de Janeiro: Livraria H. Antunes, 1935. CHRYSANTHÈME [Cecília Bandeira de Melo Rebelo de Vasconcelos]. Enervadas. Rio de Janeiro: Leite Ribeiro, 1922.

CHRYSANTHÈME [Cecília Bandeira de Melo Rebelo de Vasconcelos]. Flores modernas. Rio de Janeiro: Livraria Leite Ribeiro e Maurillo, 1921. CHRYSANTHÈME. Revista Walkyrias. Rio de Janeiro, p. 8, dezembro de 1935.

CHRYSANTHÈME: A Mulher dos Olhos de Gelo. Periódico Boletim de Ariel. Rio de Janeiro, p. 54, novembro de 1936.

FIGUEIREDO, Eurídice. Violência e sexualidade em romances de autoria feminina. Revista Interdisciplinar. São Cristóvão, v. 32, julho/dezembro, p. 137-149, 2019.

FRANÇA, Júlio. A empatia nas estratégias narrativas do horror artístico: o caso Hitchcock. In: ZANINI, Claudio; ROSSI, Cido. Vertigo: vertentes do gótico no cinema. Rio de Janeiro: Bonecker, p. 21-38, 2017. 
FRANÇA, Júlio. Introdução. In: FRANÇA, Júlio. Poéticas do mal - a literatura do medo no Brasil (1840 - 1920). Rio de Janeiro: Bonecker, p. 19-35, 2017.

GENS, Rosa. Cecília Vasconcelos e as modernas mulheres: a figuração de Chrysanthème. Anais do XV Encontro ABRALIC. Rio de Janeiro: Dialogarts, p. 1112-1119, 2016.

GORBERG, Marissa. Eva Moderna: representações de gênero em periódicos dos anos 1920: um olhar transnacional. Brasiliana: Journal for Brazilian Studies, v. 9, n. 1, p. 278-311, 2020.

GRIECO, Agripino. Evolução da Prosa Brasileira. Rio de Janeiro: Ariel, 1933. LEDGER, Sally. The New Woman: fiction and feminism at the fin de siècle. Manchester and New York: Manchester University Press, 1997.

LOBO, Luiza. Guia de escritoras da literatura brasileira. Rio de Janeiro: EdUERJ, 2006

MAIA, Mariana Fortes. Enervadas, de Mme. Chrysanthème: um simulacro autobiográfico. Revista de Letras Juçara, v. 4, n. 1, p. 59-75, 2020.

MONTENEGRO, Abelardo F. O romance cearense. Fortaleza: Tipografia Royal, 1953.

MORAES, Evaristo de. A Mulher dos Olhos de Gelo. Jornal Diário de Notícias, Segunda seção. Rio de Janeiro, p. 14, 9 fev. 1936.

MUZART, Zahidé Lupinacci. Sob o signo do gótico: o romance feminino no Brasil, século XIX. Veredas - Revista da Associação Internacional de Lusitanistas. n. 10. Santiago de Compostela, p. 295-308, 2008. Disponível em: http://ojs.lusitanistasail.org/index.php/Veredas/article/ view/420/343. Acesso em: nov. 2016.

PEREIRA, Lúcia Miguel. História da literatura brasileira: prosa de ficção (1870 a 1920). São Paulo: Editora da Universidade de São Paulo, 1988.

PINTO, Maria de Lourdes de Melo. Memória de autoria feminina nas primeiras décadas do século XX: a emergência da obra periodística de Chrysanthème. 2006. Tese (Doutorado em Literatura Comparada) Faculdade de Letras, Universidade Federal do Rio de Janeiro, 2006. 
PUNTER, David. The Literature of Terror. v. 1. London: Longman, 1996. SANTOS, Ana Paula A. dos. A licenciosidade possível em Enervadas (1921), de Mme Chrysanthème. Veredas: Revista da Associação Internacional de Lusitanistas, v. 31, p. 200-2013, 2019.

SANTOS, Ana Paula A. A vertente feminina do gótico na literatura brasileira Oitocentista. Anais eletrônicos do XV encontro ABRALIC. Rio de Janeiro: Associação Brasileira de Literatura Comparada, v. 2, p. 18471856, 2017.

SANTOS, Ana Paula A. O Gótico feminino na Literatura Brasileira: um estudo de Ânsia eterna, de Júlia Lopes de Almeida. 2017. Dissertação (Mestrado em Teoria da Literatura e Literatura Comparada) - Instituto de Letras, Centro de Educação e Humanidades, Universidade do Estado do Rio de Janeiro, Rio de Janeiro, 2017.

SHOWALTER, Elaine. A Literature of Their Own. British Women Novelists from Brontë to Lessing. Princeton, New Jersey: Princeton University Press, 1977.

SILVA, Daniel Augusto P. A prosa de fiçcão decadente brasileira e francesa (1884-1924): uma poética negativa. 2019. 132f. Dissertação (Mestrado em Teoria da Literatura e Literatura Comparada) - Instituto de Letras, Centro de Educação e Humanidades, Universidade do Estado do Rio de Janeiro, Rio de Janeiro, 2019.

SILVA, Maria de Lourdes da; MOREIRA, Helena Maria Alves; VIEIRA, Luciana Maria da Conceição. Diálogo sobre a mulher entre Madame Chrysanthème e Afrânio Peixoto na década de 1930. Fronteiras: Revista Educação Unisinos, v. 20, n. 2, p. 185-200, 2016 a.

SILVA, Maria de Lourdes da; MOREIRA, Helena Maria Alves; VIEIRA, Luciana Maria da Conceição. MMe Chrysanthème e a representação da mulher na década de 1930. Revista Mulheres e Literatura, v. 18/2은 semestre, 2016b. Disponível em: https://litcult.net/2016/08/02/mmechrysantheme-e-a-representacao-da-mulher-na-decada-de-1930-mariade-lourdes-da-silva-helena-maria-alves-moreira-luciana-maria-daconceicao-vieira/. Acesso em: fev. 2021. 
STOKER, Bram. Dracula. New York: Penguin Books, 1994.

TONIOSSO, José Pedro; ALONSO, Mariângela. Chrysanthème:

perspectivas histórico-literárias na Belle Époque brasileira. Revista EPeQ/Fafibe, Bebedouro, São Paulo, v. 1, p. 45-50, 2009.

TORPEZAS: o novo livro de Chrysanthème. Jornal Beira-Mar, Rio de Janeiro, p. 5, 18 abril de 1936.

TRÊS OPINIÕES sobre o último livro de Chrysanthème. Jornal Diário de Notícias. Segunda seção, p. 10. Rio de Janeiro, 27 outubro de 1935.

VIEIRA, Luciana Maria da Conceição. Feminismo segundo Chrysanthème no livro Famílias. Anais eletrônicos do IV Ceduce. Campina Grande:

Realize Editora, 2015. Disponível em: http://www.editorarealize.com.br/ artigo/visualizar/11199. Acesso em: 03 fev. 2021.

\section{Ana Paula Araujo dos Santos}

Doutoranda em Teoria da Literatura e Literatura Comparada pela UERJ. É bolsista CAPES, membro do grupo de pesquisa "Estudos do Gótico" (CNPq) e integrante do GT "Vertentes do Insólito Ficcional".

E-mail: ana_ads@hotmail.com

\section{Lais Alves de Souza da Silva}

Mestranda em Teoria da Literatura e Literatura Comparada pela UERJ. É bolsista CAPES, membro do grupo de pesquisa "Estudos do Gótico" (CNPq).

E-mail: lais.alvessouza@yahoo.com.br

ORCID iD: https://orcid.org/0000-0002-3584-7514 